\title{
Recrystallisation in the Semi-Solid State in 7075 Aluminium Alloy
}

\author{
H.V. Atkinson ${ }^{1}$, K. Burke ${ }^{2}$, G. Vaneetveld ${ }^{3}$ \\ ${ }^{1}$ Department of Engineering, University of Leicester, University Rd., Leicester, LE1 7RH, UK. Formerly \\ Department of Engineering Materials, Hadfield Building, University of Sheffield, Mappin St., Sheffield, S1 \\ 3JD, UK. \\ URL: www.le.ac.uk/eg/research/groups/mechmats e-mail: hva2@le.ac.uk \\ ${ }^{2}$ Formerly Department of Engineering Materials, Hadfield Building, University of Sheffield, Mappin St., \\ Sheffield, S1 3JD, UK. \\ URL: www.shef.ac.uk \\ e-mail: kjburke@btinternet.com \\ ${ }^{3}$ ThixoUnit Ulg, PiMW B56, University of Liège-Sart-Tilman, 4000 Liège, Belgium. \\ URL: www.metaux.ulg.ac.be \\ e-mail: G.Vaneetveld@ulg.ac.be
}

\begin{abstract}
: 7000 series aluminium alloys are currently machined from the wrought state with much waste. There is therefore a motivation to identify effective near net shaping routes. Semi-solid processing is one such potential route. It relies on the thixotropic behaviour of alloys with non-dendritic spheroidal microstructures. In the semisolid state the material thins when sheared and will flow to fill the die. When worked material is reheated, it recrystallises and moving into the semi-solid state, the required spheroidal microstructure develops. Here we examine the early stages of spheroid formation in 7075 aluminium alloy reheated from the as-supplied T6 condition. This alloy is very resistant to recrystallisation in the solid state due to the presence of dispersoid particles pinning grain boundaries. There is a sudden increase in the appearance of spheroidal grains. There is a close association with the position of the first liquid to form. On reheating as-supplied material to around $580^{\circ} \mathrm{C}$ (fraction of liquid $\sim 5 \%$ ), a fully spheroidal microstructure can be obtained.
\end{abstract}

Key words: 7075 aluminium alloys, recrystallisation, pinning force, thixoforming, semisolid.

\section{INTRODUCTION}

The strongest wrought aluminium alloys are those in the 7XXX series. These are based on the Al-Zn-Mg$\mathrm{Cu}$ system. There are three types of particles present: fine strengthening precipitates; dispersoid particles; and constituent particles [1]. Backerud et al. [2] have found that the solidus, on cooling, for 7075 lies between $466^{\circ} \mathrm{C}$ and $470^{\circ} \mathrm{C}$, depending on the cooling rate. For 7075 , the age hardening precipitates are $\mathrm{MgZn}_{2}$ for ageing temperatures less than $200^{\circ} \mathrm{C}$ [3]. $\mathrm{Al}_{2} \mathrm{CuMg}$ phase is also precipitated [3]. The dispersoid particles are soluble only in liquid and include $\mathrm{Al}_{12} \mathrm{Mg}_{2} \mathrm{Cr}$ and $\mathrm{Al}_{18} \mathrm{Mg}_{3} \mathrm{Cr}_{2}$ (E-phase) [4]. These are $0.5-2 \mu \mathrm{m}$ in size and play an essential role in pinning grain and sub-grain boundaries. E-phase, in particular, is of the appropriate size and volume fraction to severely inhibit recrystallisation. Fe and $\mathrm{Si}$ are present in the alloy as impurities and give rise to constituent particles $1-30 \mu \mathrm{m}$ in size, which are detrimental to mechanical properties [3] and are resistant to dissolution.

7075 is usually supplied in the worked and heat treated state. Provided the melting sequence matches the solidification sequence, according to Backerud et al. [2], the first liquid to form during reheating would be based on the sub-micron sized $\mathrm{MgZn}_{2}$ at around $470^{\circ} \mathrm{C}$. This would be followed by a reaction between $\mathrm{Al}$ and $\mathrm{Mg}_{2} \mathrm{Si}$ at around $550^{\circ} \mathrm{C} / 560^{\circ} \mathrm{C}$.

Recrystallisation in the solid state is defined as the formation and migration of large angle grain boundaries where the driving force is the decrease in the free energy from the decrease in dislocations. There has been little discussion in the literature of recrystallisation (or a phenomenon which gives microstructural features very similar to recrystallisation i.e. new, relatively equiaxed, grains nucleating and growing in a structure of elongated grains) at temperatures above the solidus. This paper is concerned with this phenomenon. The work has been more fully reported elsewhere [5].

Thixoforming involves forming alloys in the semisolid state to near net shape (e.g. as-reviewed in $[6,7])$. The required spheroidal microstructure can be obtained by a number of routes, including the Strain Induced Melt Activated method (SIMA) [8] and 
Recrystallisation and Partial melting (RAP) [9]. The material is worked, e.g. by extrusion, and then reheated. Recrystallisation occurs (generally below the solidus) and the liquid penetrates the recrystallised boundaries to give the spheroidal structure. The first liquid to form tends to form at grain boundaries because these are generally areas with high solute concentrations.

Net shaping thixoforming of wrought alloys such as $7075[10-16]$ is of considerable practical significance because these alloys are often shaped by costly and wasteful machining operations. Understanding the development of the spheroidal microstructure will enable process optimisation.

\section{EXPERIMENTAL METHOD}

\subsection{Material and Microstructural Examination}

The material had composition (wt \%): $\mathrm{Al} 5.70 \mathrm{Zn} 2.54 \mathrm{Mg} 1.34 \mathrm{Cu} 0.21 \mathrm{Fe} 0.20 \mathrm{Cr} 0.04 \mathrm{Mn} 0.10 \mathrm{Si}$ $0.10 \mathrm{Zr} 0.05 \mathrm{Ti}$ and was supplied in the T6 heat treated state by Apollo Metals Ltd with an extrusion ratio of 16:1. The samples were ground using 200, 400, 800 and 1200 grit papers, polished with 6 micron diamond paste through to a final polish with $1 / 4$ micron using 'Silco' liquid. They were then etched using Barkers etch ( $2 \%$ fluorboric acid) at $20 \mathrm{~V}$ for 1.5 minutes, with a stainless steel cathode. The samples were viewed under polarised light with the polariser and analyser crossed to reveal grain orientation. A gypsum prism was used to enhance the colour of the images obtained using a Reichert Jung Polyvar microscope.

\subsection{Heating Tests to Investigate Recrystallisation at Different Temperatures}

Samples $2.5 \mathrm{mmx} 10 \mathrm{mmx} 15 \mathrm{~mm}$ (with the extrusion direction parallel to the surface with the largest area) were heated in a salt bath. To suspend the specimens in the bath, one end of a piece of nichrome wire was coiled around the sample to form a cage. A hole $1.3 \mathrm{~mm}$ in diameter was drilled in each sample and a $1 \mathrm{~mm}$ diameter thermocouple inserted. The sample was heated in the salt bath for 10 minutes from the time the sample entered the furnace.

\section{RESULTS}

A typical starting material microstructure is shown in Fig.1. The grains are unrecrystallised as shown by the contrast variations within the elongated grains. During isothermal tests, the fraction of 'spheroidal' grains and the spheroidal grain size increase (Fig. 2).

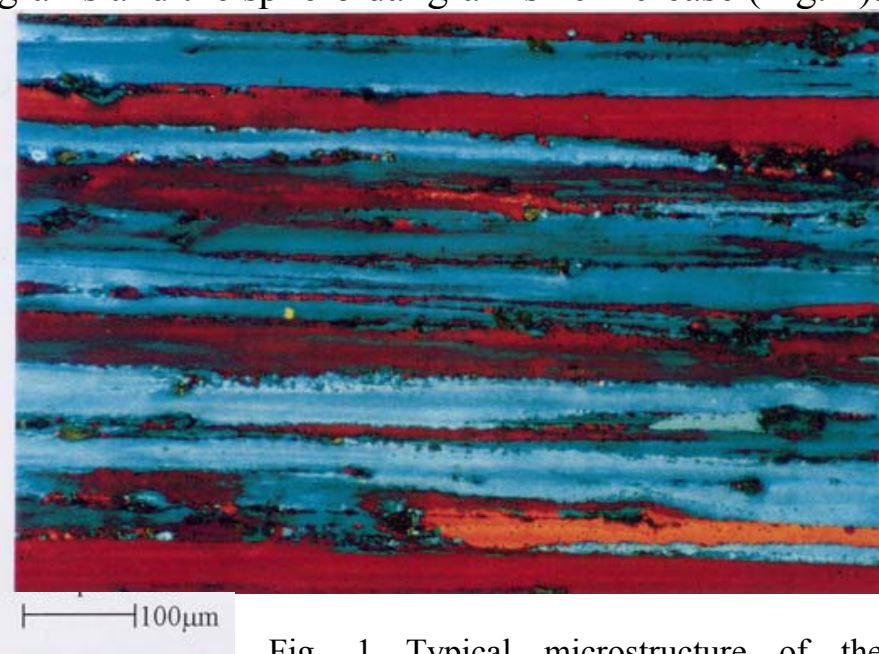
commercial starting material.
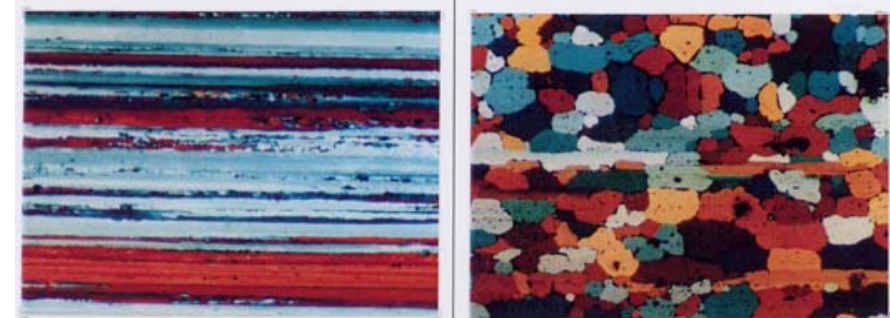

Temperature: $490^{\circ} \mathrm{C}$

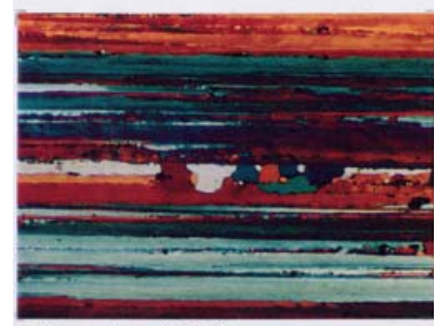

Temperature: $513^{\circ} \mathrm{C}$

Temperature: $558^{\circ} \mathrm{C}$
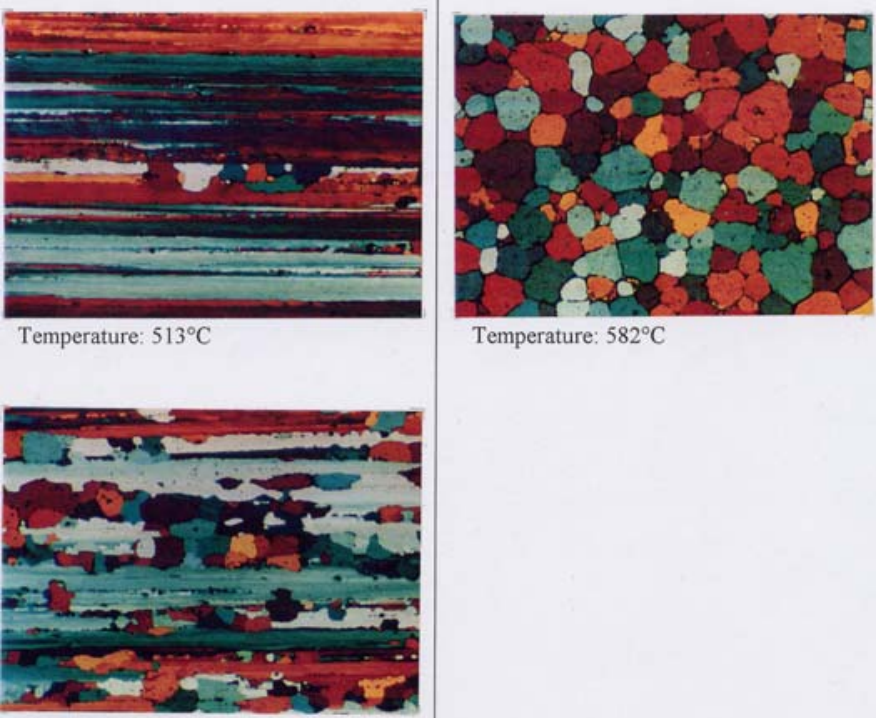

Temperature: $540^{\circ} \mathrm{C}$

$\longmapsto 100 \mu \mathrm{m}$ Fig. 2 Micrographs of material heated for 10 minutes in a salt bath at different temperatures within the solidification range and quenched in brine.

In samples heated at temperatures up to $515^{\circ} \mathrm{C}$, there are very few incipient spheroidal grains, even after 
being held at temperature for 1 hour. When the material is heated to $558^{\circ} \mathrm{C}$ or above, the material is almost entirely spheroidal after 10 minutes. The microstructure of the material quenched from $513^{\circ} \mathrm{C}$ after 10 minutes is shown in more detail in Fig. 3.

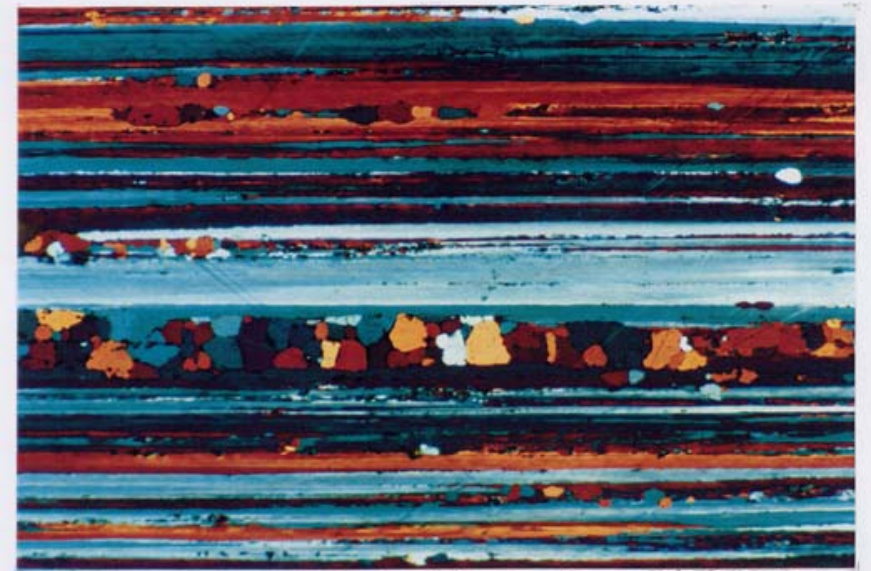

a): Samples etched in Barkers etch and viewed under polarised light with the polariser and analyser crossed
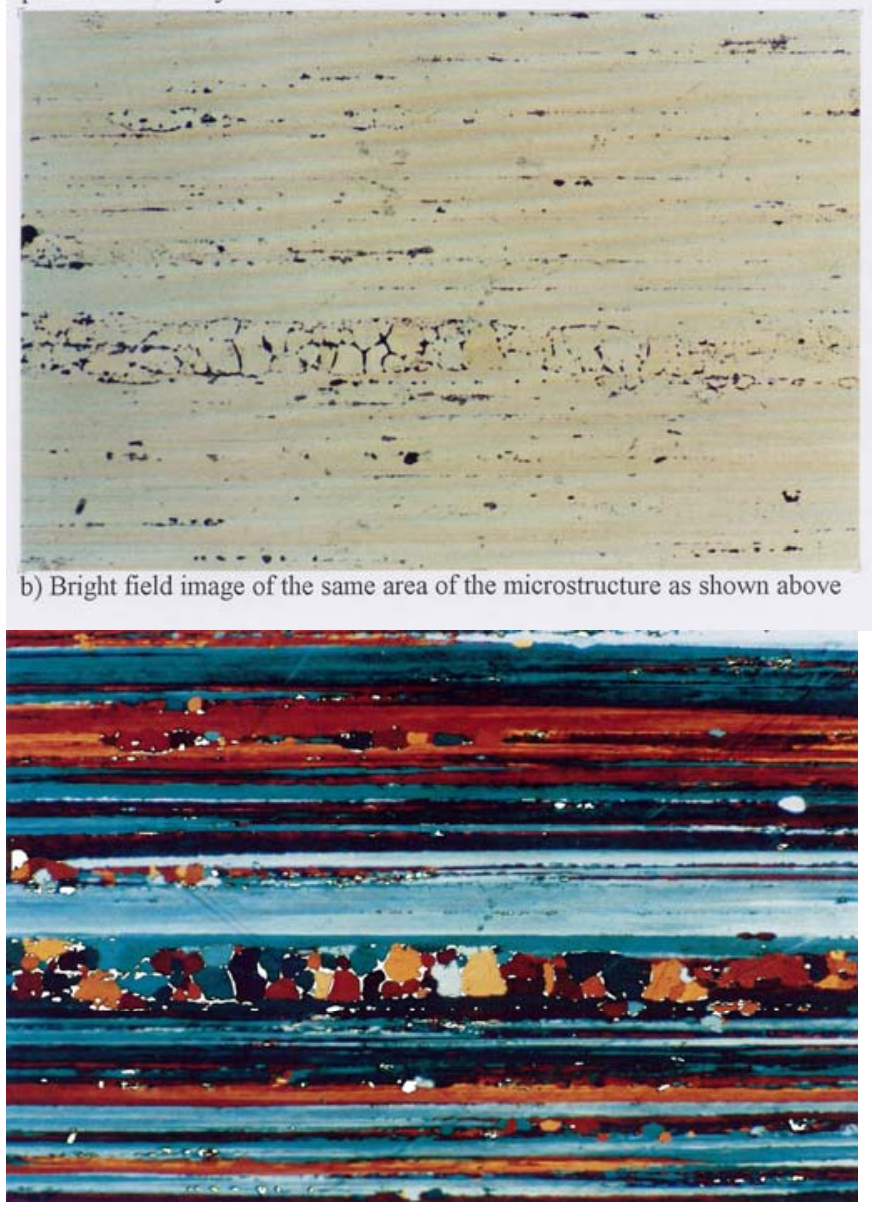

c) 'Black' areas in b) converted to white and superimposed on a).

\section{$\longmapsto 100 \mu \mathrm{m}$}

Fig. 3 Material after heating for 10 minutes in a salt bath at $513^{\circ} \mathrm{C}$ and quenching in brine.

Fig. $3 \mathrm{~b}$ ) is the bright field image and shows where pools of liquid are present. The dark areas are assumed to be quenched liquid because of EDX evidence $[5,13]$ which shows a concentration of $\mathrm{Cu}$,
$\mathrm{Zn}$ and $\mathrm{Mg}$ in this region, elements expected to be in the liquid. The pools of liquid coincide with the presence of incipient spheroidal grains in Fig. 3 a). This is proved in Fig. 3 c) by making a transparent overlay of Fig. 3 b) (with the 'liquid' shown as white) and superimposing it on Fig. 3 a). In general, incipient spheroidal grains are associated with pools of liquid. There are few examples of liquid being present without an incipient spherhoidal grains and few examples of the reverse. A higher magnification image is shown in Fig. 4 to give greater confidence about the observation.

a)
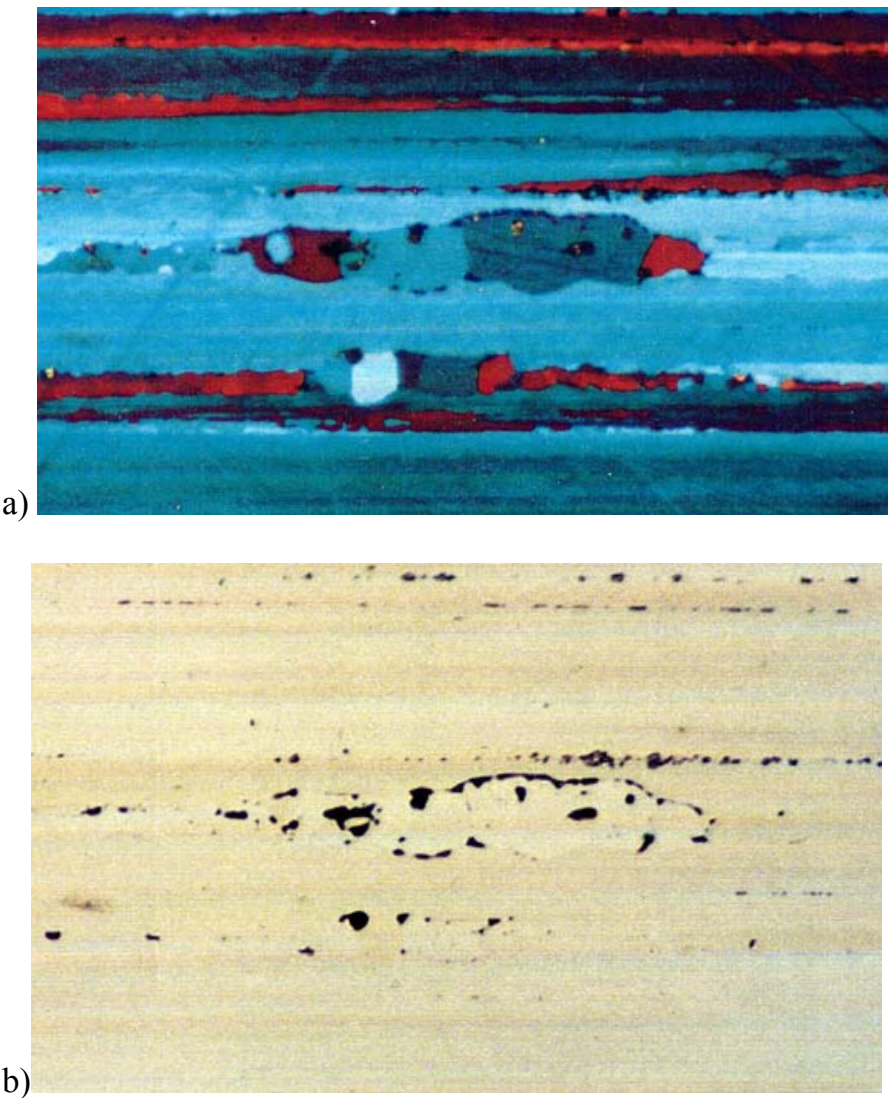

50 um Fig. 4 Higher magnification of Fig. 3 material a) Barkers etch and b) bright field of same area.

\section{DISCUSSION}

The starting material (Fig. 1) is unrecrystallised and in the precipitation hardened state following T6 heat treatment. Distributed through the matrix are the ageing precipitates (mainly $\mathrm{MgZn}_{2}$ ). Dispersoids such as E-phase will be pinning the grain boundaries. Evidence for these microstructural features from TEM is given in [11]. According to Backerud et al. [2], on reheating to above the solidus the first reaction to occur will be the formation of liquid by the reaction of $\mathrm{MgZn}_{2}$. We then need to 
explain why the 'recrystallisation' starts to occur at temperatures which are above the solidus but below about $540^{\circ} \mathrm{C}$. We hypothesise that the E-phase and other dispersoids pinning the grain boundaries start to dissolve in the liquid and this initiates the recrystallisation as the boundaries start to become unpinned. There is TEM evidence in $[11,15]$ to show that the precipitate free zones by boundaries are relatively narrow $(\sim 100 \mathrm{~nm})$. It is therefore likely that the E-phase and other dispersoids will be in close proximity to $\mathrm{MgZn}_{2}$ as the $\mathrm{MgZn}_{2}$ particles themselves react to form liquid. A possible mechanism is that, at temperature, sections of boundary between pinning particles are bulging into the matrix. As soon as a section of boundary touches a pool of liquid, the liquid spreads along the boundary towards a pinning particle. In contact with liquid, the pinning particle dissolves and the boundary becomes unpinned.

The quenched liquid is rich in $\mathrm{Cu}, \mathrm{Zn}$ and $\mathrm{Mg}$, in comparison with the matrix. This supports the argument that the first liquid to form is associated with the hardening precipitates, rather than the dispersoids (which contain $\mathrm{Cr}$ along with $\mathrm{Al}$ and $\mathrm{Mg}$ ).

It appears that, as soon as liquid is present at boundaries, the grains begin to grow, with the boundaries showing the characteristic curved shape as they expand into other material (Fig. 4 b)). There are some liquid pockets in 'necklace' structures at recrystallised boundaries that are migrating. This may occur as unpinned boundaries start to sweep through, gathering up tiny liquid pools present in the matrix as ageing precipitates start to form liquid.

\section{CONCLUDING REMARKS}

At temperatures above the solidus but below about $515^{\circ} \mathrm{C}, \quad 7075$ remains predominantly unrecrystallised. Above this temperature, recrystallised grains grow, probably because the pinning dispersoids dissolve. These findings affect the heating conditions for thixoforming 7075 .

\section{ACKNOWLEDGEMENTS}

The authors would like to thank the following for support: Lucas Advanced Engineering Systems Development; University of Sheffield Department of Engineering Materials, University of Leicester Department of Engineering, the COST 541 Project, Engineering and Physical Sciences Research Council, the University of Liege, and the First Europe Project. In addition, Prof C M Sellars and Prof F J Humphreys are thanked for helpful discussions and $\mathrm{Mr}$ Andrew Norman for assistance with image manipulation.

\section{REFERENCES}

1. J.T. Staley, In: Proc. $3^{\text {rd }}$ Int. Conf. on Aluminium Alloys; L. Arnberg, O. Lohne, E. Nes, N. Ryum, eds., Trondheim, Norway, (1992) Norwegian Institute of Technology, SINTEF, pp. 107-29.

2. L. Bäckerud, E. Król, J. Tamminen, Solidification characteristics of aluminium alloys, vol. 1: Wrought Alloys, Skan Aluminium, Oslo (1986).

3. I. J. Polmear, Light alloys: metallurgy of the light metals, $3^{\text {rd }}$ ed. Arnold, London (1995).

4. Ayer Raghavan, J.Y. Koo, J.W. Steeds and B. K. Park, Metall. Trans. A 16A (1985)1925-36.

5. H.V. Atkinson, K. Burke and G. Vaneetveld, 'Recrystallisation in the Semi-Solid State in 7075 Aluminium Alloy', accepted for publication in Mater. Sci. Engng. A.

6.. Z. Fan, Internat. Mater. Rev., 47 (2002) 49-85.

7. H. V. Atkinson, Prog. Mater. Sci. 50 (3) (2005) 341-412.

8. K.P. Young, C.P. Kyonka, J.A. Courtois. Fine grained metal composition. US Patent No. 4,415,374; 30 March 1982.

9. D.H. Kirkwood, C.M. Sellars, L.G. Elias-Boyed, Thixotropic materials. European Patent No. 0305375 B1; 28 October 1992.

10. Hsin-Nan Chou, G. Govender, L. Ivanchev, Solid State Phenomena 116-117 (2006) 92-95.

11. S. Chayong, H.V. Atkinson, P. Kapranos, Mater. Sci. and Technol. 20 (2004) 490-6.

12. S. Chayong, H.V. Atkinson, P. Kapranos, Mater. Sci. Engng. A390 (2005) 3-12.

13. K. Burke, 'Semi-Solid Processing of Aluminium 7075', PhD Thesis, University of Sheffield, 1998.

14. G. Vaneetveld, A. Rassili, J. Lecomte-Beckers, H.V. Atkinson, Solid State Phenomena 116-117 (2006) 762-5.

15. S. Chayong, 'Thixoforming Processing of Aluminium 7075 Alloy', PhD Thesis, University of Sheffield, 2002.

16. W. Jirattiticharoean, 'Development of thixoforming and heat treatment for 7000 series alloys', PhD Thesis, University of Sheffield, 2005. 